\title{
Assessment of Physical Fitness and Its Association with Sympathetic Activation Among the Students of Pokhara University, Nepal
}

\author{
Bijay Subedi $^{1,}$, , Bishwas Subedi ${ }^{2}$, Sapana Bhandari ${ }^{1}$, Sabin Poudel ${ }^{1}$, Khem Raj Joshi ${ }^{1}$ \\ ${ }^{1}$ School of Health \& Allied Sciences, Faculty of Health Sciences, Pokhara University, Pokhara, Nepal \\ ${ }^{2}$ School of Public Health and Community Medicine, B. P. Koirala Institute of Health Sciences, Dharan, Nepal
}

\section{Email address:}

bijsub12@gmail.com (Bijay S.), bishwas.subedi99@gmail.com (Bishwas S.), sapnabhandary48@gmail.com (Sapana B.), sabinpoude1941@gmail.com (Sabin P.), khemraj_pu@yahoo.com (Khem R. J.)

${ }^{*}$ Corresponding author

\section{To cite this article:}

Bijay Subedi, Bishwas Subedi, Sapana Bhandari, Sabin Poudel, Khem Raj Joshi. Assessment of Physical Fitness and Its Association with Sympathetic Activation Among the Students of Pokhara University, Nepal. European Journal of Preventive Medicine.

Vol. 8, No. 5, 2020, pp. 83-90. doi: 10.11648/j.ejpm.20200805.15

Received: September 16, 2020; Accepted: October 5, 2020; Published: October 13, 2020

\begin{abstract}
A 3-minute step test provides a feasible, low cost procedure with minimal risk to the participant for assessing physical fitness compared to maximal exercise testing. Test assessing the autonomic function (sympathetic wing) evaluates the cardiovascular reflex like increased blood pressure triggered by performing specific stimulating maneuvers such as Isometric Hand Grip Test (IHGT). We assessed \& categorized the fitness level using a 3 min step test and its association with sympathetic activation during IHGT in university level students with sound health. There is increasing evidence of an association between Physical Fitness and academic performance. Two hundred consenting healthy students studying at Pokhara University (largest in western region of Nepal) aged 17-25 years underwent sub-maximal exercise as per the protocol of 3 min-step test given by Young Man's Christian Associations (YMCA) to categorize as good \& poor being based on recovery heart rate. Each groups undertook IHGT \& changes in Diastolic Blood Pressure (DBP) were noted. About two third of the study participants were female and 70\% of total students were of poor fitness level. Fitness level and sex was significantly associated $(\mathrm{P}=0.041, \mathrm{OR}=1.92, \mathrm{CI}=1.024$ 3.606). More of the male participants had good fitness in comparison to that of the female participants (38.9\% vs $24.8 \%)$. Differences in Diastolic Blood Pressure during IHGT and at rest (assess sympathetic activation during stress) was significantly associated with fitness level $(\mathrm{P}<0.001, \mathrm{OR}=1.32, \mathrm{CI}=1.201-1.446)$. Majority of university level students had poor fitness with high proportion in female. Students with good fitness level had good sympathetic activation to physical stress as compared to those with poor fitness level. Physical fitness (Cardiorespiratory fitness) is proven to induce angiogenesis in the motor cortex and increases blood flow, improving brain vascularization which could affect cognitive performance. So measuring physical fitness of university students at the time of admission or during the study period could help to predict their academic achievements through their reasoning function and ability of coping various stresses that they might encounter during academic journey. Those with poor physical fitness would be advised to improve the fitness by promoting physical activity.
\end{abstract}

Keywords: Physical Fitness, Academic Performance, University Students, Autonomic Response, 3 Min-step Test, Isometric Hand Grip Test, Nepal

\section{Introduction}

\subsection{Physical Fitness Assessment}

General physical fitness (PF) is a state of ability to perform sustained physical work characterized by an effective integration of cardiorespiratory endurance, strength, flexibility, coordination, and body composition. Gold standard for assessing cardiorespiratory fitness involves maximal exercise testing like treadmill or cycle ergometer in conjunction with collection and evaluation of expired gases [1]. Additionally maximal exercise tests require costly equipment, trained staff 
and are labor intensive. Different standardized submaximal test like 1.5 mile run-walk, Canadian Standardized Test for Fitness (CSTF) and modified step test have been developed to evaluate exercise capacity [2]. Submaximal exercise testing is preferable to maximal exercise testing in low income country like Nepal, which is cost effective and can be undertaken by the manpower at hand and is also compatible with contraindicated conditions like cardiopulmonary, musculoskeletal, neuromuscular impairments, dyspnea, fatigue, weakness, and pain. It overcomes many of the limitations of maximal exercise testing like cost, safety, and thus submaximal exercise testing provides a feasible low cost alternative method of assessing cardiovascular fitness with minimal risk to the participant compared to maximal exercise testing [3]. Three minutes step test assesses the fitness level based on how quickly heart rate recovers after exercise.

\subsection{Cardiovascular Autonomic Response}

In normal individuals, the heart rate is subjected to constant fluctuation due to sympathetic and parasympathetic modulation of sinus node activity. Increased efferent vagal activity (parasympathetic) is characterized by reduced heart rate, whereas sympathetic stimulation increases heart rate [4]. Due to the close link between autonomic nervous system (ANS) and the function of Sino-atrial node \& vasomotor center at medulla, heart rate along with Blood Pressure (BP) are fluctuated in response to exercise which reflects the changes in cardiac autonomic control. This neural link creates the basis of assessment of autonomic functions through the measurement of differences of DBP during exercise \& basal condition [5]. It is possible that different exercise intensities also have distinct effects on cardiovascular changes through modulation of autonomic nervous system. Isometric Hand Grip Test (IHGT) provides a beneficial and easy way to stimulate the cardiovascular system and state the role of autonomic nervous system (sympathetic nervous system) in response to the exercise. Therefore, it is important to assess the integrity of the cardiovascular system by isometric exercise specifically as sympathetic excitatory maneuver (handgrip maneuver). Result of IHGT is interpreted as the difference between the highest diastolic pressure during test and the average diastolic pressure at rest, which should normally be higher than $15 \mathrm{mmHg}$ [6]. Isometric muscle contraction tempts large increase in mean arterial pressure, heart rate and muscle sympathetic nerve activity (MSNA) with a minor rise in central hemodynamics [7]. The increases in MSNA are thought to result, primarily from activation of the muscle metaboreflex or exercise pressor reflex in the exercising muscle [8]. Ischemic metabolites produced during muscular contraction evoke cardiovascular and vasomotor reflexes, which are thought to be originated in sensory receptors of particular muscles [9]. Although low cardiorespiratory fitness (CRF), physical inactivity, and obesity are associated with impaired autonomic function, they are also extensively interrelated [10].

The aims of this study were to assess \& categorize the physical fitness level (good \& poor) using 3 min step test and its association with autonomic function (sympathetic nerve activation) during isometric handgrip test amongst healthy university level students. Most of the studies have been conducted to assess the sympathetic nerve activity among different patients like diabetics and hypertensive. Our aim was to assess the autonomic nervous system activity (sympathetic activation during exercise) in apparently healthy young adult university students of different fitness groups that have been categorized by 3-min step test. Adequate justification have been reported on the association between physical fitness and academic performance which has been postulated as PF's positive effects on cognitive function and performance in attention tasks, or by its effects on depression, stress, and sleep quality [11]. Since there are rare reports on physical fitness \& autonomic responses with physical stress in different fitness level nationally and even internationally, this study is an endeavor to quantify the cardiorespiratory fitness level under sub-maximally controlled exercise. Apart from explaining the cardiovascular autonomic regulatory mechanism, this study is expected to make background for developing normative data on fitness level versus autonomic responses, which may be used for health promotion, for upgrading academic performance of university students and may even serve clinical purpose.

\section{Materials and Methods}

A cross-sectional study was conducted among healthy students age ranging from 17-25 years of age, studying at School of Health and allied sciences, Pokhara University. The study duration was of 1 year period from June 2018 to June 2019.

\subsection{Sample Size}

All healthy consenting undergraduate students who didn't have any neuromuscular and autonomic disorder and clinical diagnosis of hypertension, diabetes, cardiovascular diseases etc. were included in the study. The sample size of 200 was obtained for the study by using formula $n=z^{2} \mathrm{pq} / \mathrm{e}^{2}$, considering the prevalence of $17 \cdot 0 \%(16 \cdot 8-17 \cdot 2)$ for southeast Asia from the study published in The lancet 2012 by Hallal PC et al. [12]

Samples were selected randomly from each undergraduate programs of school of Health and Allied Sciences i.e. Bachelor in Public Health, B. Sc. Medical Lab Technology, BSc. Nursing, Bachelor in Pharmaceutical Sciences and Bachelor of Physiotherapy. Each programs has 4 classes from $1^{\text {st }}$ year to $4^{\text {th }}$ year and 10 samples were selected randomly from every classes.

\subsection{Data Collection}

\subsubsection{Variables Under Study}

i. Anthropometric variables: Age, sex, height, weight, body mass index (BMI).

ii. Cardiorespiratory variables: Blood pressure, respiratory rate, and pulse rate, recovery heart rate (RHR)

iii. Maximum differences in diastolic blood pressure (DBP) 
during \& after the isometric hand grip test.

\subsubsection{Data Recording Procedures}

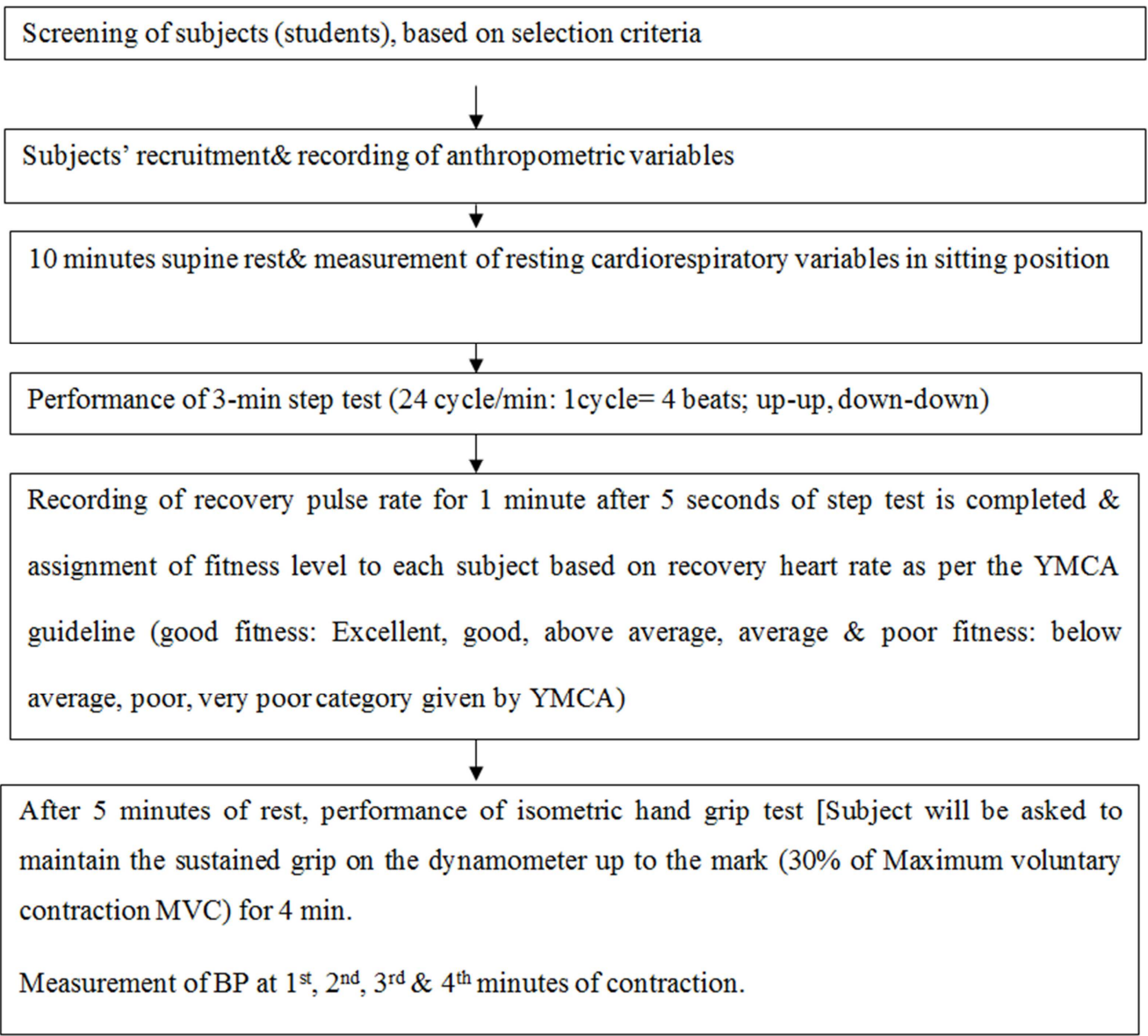

Figure 1. Flow chart for procedure of recording the variables.

The BP response was calculated as Highest DBP during the test - Baseline DBP.

Ranges [6]

$\geq 16 \mathrm{mmHg}$ was taken as Normal.

$\leq 15 \mathrm{mmHg}$ as Below Normal

Table 1. Age-adjusted standards recovery heart rate based on guideline published by YMCA for men \& women [13].

Ratings for Men, Based on Age

\begin{tabular}{llllll}
\hline & $\mathbf{1 8 - 2 5}$ & $\mathbf{2 6 - 3 5}$ & $\mathbf{3 6 - 4 5}$ & $\mathbf{4 6 - 5 5}$ & $\mathbf{5 6 - 6 5}$ \\
\hline Excellent & $50-76$ & $51-76$ & $49-76$ & $56-82$ & $60-77$ \\
Good & $79-84$ & $79-85$ & $80-88$ & $87-93$ & $86-94$ \\
Above Average & $88-93$ & $88-94$ & $92-88$ & $95-101$ & $97-100$ \\
Average & $95-100$ & $96-102$ & $100-105$ & $103-111$ & $103-109$ \\
Below Average & $102-107$ & $104-110$ & $108-113$ & $113-119$ & $111-117$ \\
Poor & $111-119$ & $114-121$ & $116-124$ & $121-126$ & $119-128$ \\
Very Poor & $124-157$ & $126-161$ & $130-163$ & $131-159$ & 128 \\
\hline
\end{tabular}

Ratings for Women, Based on Age

\begin{tabular}{llllll}
\hline & $\mathbf{1 8 - 2 5}$ & $\mathbf{2 6 - 3 5}$ & $\mathbf{3 6 - 4 5}$ & $\mathbf{4 6 - 5 5}$ & $\mathbf{5 6 - 6 5}$ \\
\hline Excellent & $52-81$ & $58-80$ & $51-84$ & $63-91$ & $60-92$ \\
Good & $85-93$ & $85-92$ & $89-96$ & $95-101$ & $97-103$ \\
Above Average & $96-102$ & $95-101$ & $100-104$ & $104-110$ & $106-111$ \\
Average & $104-110$ & $104-110$ & $107-112$ & $113-118$ & $113-118$ \\
Below Average & $113-120$ & $113-119$ & $115-120$ & $120-124$ & $119-127$ \\
Poor & $122-131$ & $122-129$ & $124-132$ & $126-132$ & 111 \\
Very Poor & $135-169$ & $134-171$ & $137-169$ & 121 & $129-135$ \\
\hline
\end{tabular}




\subsection{Data Analysis}

The collected data were entered into Microsoft Excel 2016 and converted into Statistical Package for Social Sciences 11.5 version for further analysis. For descriptive analysis frequencies, mean and percentages were calculated and presented in pie charts. Similarly, for inferential statistics, Chi-square test was applied to assess the association between different variables.

\section{Results}

\subsection{Figures}

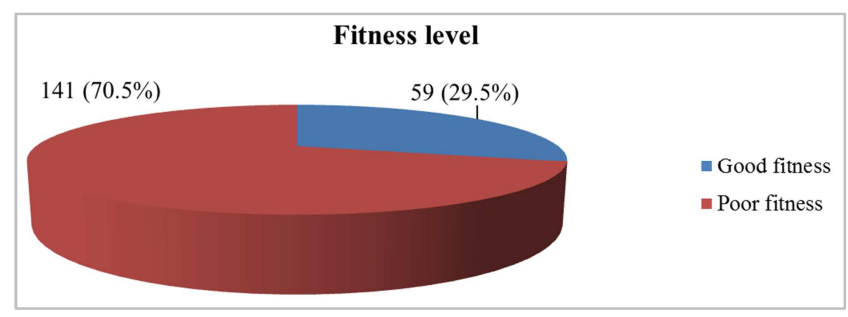

Figure 2. Fitness level of students.

A total of 200 participants were included in the study among which about two third (66.5\%) of the study participants were female. During anthropometric measurement the majority (90.5\%) of the study participants were of normal Body Mass Index and only $9.5 \%$ of the participants were overweight. Figure 2 shows that almost two third $(70 \%)$ of the study participants were of poor fitness level.

Figure 3 illustrates the difference of highest Diastolic blood pressure (DBP) during IHG test and baseline DBP. Participants were categorized as normal $\geq 16 \mathrm{mmHg}$ and $\leq 15$ $\mathrm{mm} \mathrm{Hg}$ as below normal. Majority (83\%) of the participants were found to be normal and only $17 \%$ were below normal.

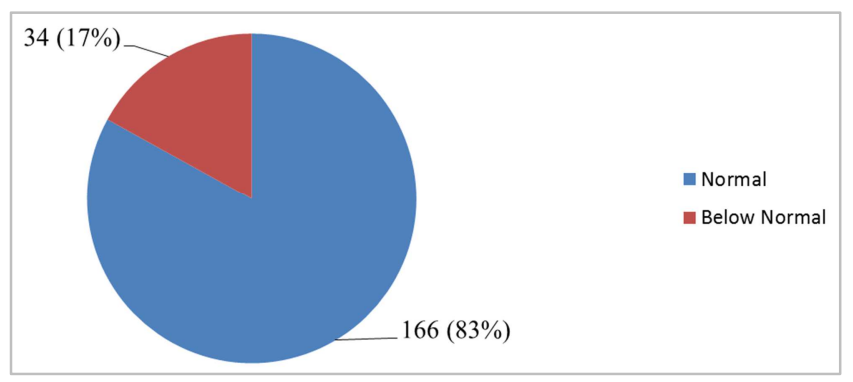

Figure 3. Difference of highest DBP at IHG and baseline DBP.

\subsection{Tables}

Table 2 shows the significant association between fitness level and sex $(\mathrm{P}=0.041)$. More proportion of males $(38.9 \%)$ had good fitness level as compared to females (24.8\%). Likewise, majority of females $(75.2 \%)$ had poor level of fitness as compared to males (61.2\%). Similarly, it showed that male were 1.922 times more likely to be in good fitness level as compared to the female.

Table 2. Association of fitness level with sex.

\begin{tabular}{llllll}
\hline Characteristics & Fitness level & & \multirow{2}{*}{ Total } & \multirow{2}{*}{ P-value } & \multirow{2}{*}{ Odds Ratio (CI) } \\
\hline Sex & Good N (\%) & Poor N (\%) & 67 & \multirow{2}{*}{$0.041^{*}$} & \multirow{2}{*}{$1.922(1.024-3.606)$} \\
\hline Male & $26(38.8)$ & $41(61.2)$ & $100(75.2)$ & 133 & \\
\hline
\end{tabular}

Table 3 shows that the association between physical fitness level and differences in diastolic blood pressure during isometric hand grip test and at rest was found to be highly significant $(\mathrm{P}<0.001)$. All the participants with good fitness level had normal difference in DBP at rest and during IHGT, while about one forth $(24.11 \%)$ of the participants who were of poor fitness level fall under below normal category. Likewise the study showed that those who were of good fitness level were 1.318 times more likely to have normal difference in DBP at rest and during IHGT than those who were of poor fitness level.

Table 3. Association between physical fitness level and differences in diastolic blood pressure during isometric hand grip test and at rest.

\begin{tabular}{llllll}
\hline Characteristics & Difference in DBP & & \multirow{2}{*}{ Total } & \multirow{2}{*}{ P-value } & \multirow{2}{*}{ Odds Ratio (CI) } \\
\cline { 1 - 4 } Fitness Level & Normal N (\%) & Below Normal N (\%) & & 59 & \multirow{2}{*}{$1.318(1.201-1.446)$} \\
\hline Good & $59(100)$ & 0 & 141 & $<0.001 *$ & 1.318 Poor \\
\hline
\end{tabular}

\section{Discussion}

The study was carried out with the aim of assessing the cardiorespiratory fitness level of healthy University level students being based on the basis of 1-min post exercise recovery heart beat count after a sub-maximal exercise, YMCA 3-min step test. Cardiovascular sympathetic autonomic response in different fitness level (good \& poor) students against physical stress was assessed through IHGT (One of the 5 batteries of Autonomic Function Test). Since it is well known that acute bout of exercise is known to change a number of cardiovascular parameters, we focused basically on the pattern of change in DBP during physical stress (IHGT) as compared to basal DBP.

At Pokhara University, the number of undergraduate female were found to be higher than that of number of counterpart (Female; 66.5\% Vs. Male 33.5\%). Almost 
similar scenario has been observed in The University of Texas Health Science Centre at San Antanio, USA (Female $69 \%$ Vs. Male 31\%) [14]. In contrast, many of the top ranked University in India have higher number of male students as compared to female. For instance, Indian Institute of Technology, Kanpur has $87 \%$ enrollment of male students [15]. This implies the thriving participation of females in higher education in the urban part of Nepal along with their augmented interest towards Health Science sector.

Majority $(90.5 \%)$ of the students at University's School were of normal Body Mass Index and only 9.5\% of the participants were overweight. However the report of American College Health Association has stated that the situation of overweight is worse on college and university campuses in western nations, with $28.8 \%$ of female college students and $39.4 \%$ of male college students being classified as overweight or obese [16]. This figure clarify that almost all students in our university are within normal BMI.

Fitness level of students at SHAS, Pokhara University, was found to be dominantly poor (Poor fitness level 70.5\% vs. good fitness level 29.5\%). Similar to our finding, with multiethnic studies, Kenya, S., Brodsky, $M$ et al found that, students from Asian and African countries have the lowest levels of physical activity participation, whereas Caucasian students show the active participation in physical activities [17]. This type of trend in Asian countries have been somehow explained by Cardinal, B. J., Lee, J. Y., et al. who have found that traditionally as in Asian countries, low priority is given to physical activity because of the emphasis on education of the mind over the physical development of the body. The meagre time allocated set for physical activities but plenteous time for sedentary behaviors may not only affect BMI but could also taper physical fitness, which impair academic performance [18]. Asian students also tend to devote most of their time to academic- work (e.g., reading, studying) leaving little time for social or recreational activities such as physical activity [19]. With reference to Cardinal, B. J, this could be one of the causes for poor fitness level in Nepalese students too. Other reasons for low fitness level in students in Asian countries is illuminated by Yan, Z., et al. who explained that low physical activity participation rates may also be attributed to the prioritization of subjects, such as Mathematics, Literacy, and English [20] over physical education programs and physical activity programs. Only limited number of schools in Asia have comprehensive physical education programs [16] and physical activity programs in educational settings. In support of our study, Lewis, M. V et al explained that people in Asia may not be as aware of the benefits of exercise compared to as those in America \& Keating, X. D et al enlightened on poorly developed exercise facility infrastructures as one of the causes of poor fitness in Asian countries [21, 22]. Knowledge of physical activity has been found to be a predictor of physical activity \& thus fitness for adolescents and youth [23]. However, it has rarely been reported as being related to physical activity for adults [24]. Sallis and colleagues concluded that although acquaintance with physical activity is necessary, it alone does not predict physical activity \& ultimately physical fitness [25]. Zi Yan et al stated that Asian students attending American colleges and universities are reported to have low levels of physical activity participation, which may hinder their ability to realize their full human potential (i.e., cognitively, physically, socially). As a result the youth of Asia are at increased risk for sedentary living and the associated health risks already identified [16].

Our study revealed the significant association of sex with fitness level. Females had significantly poor level of fitness as compared to males $(p<0.05)$. Similarly, it indicated that males were 1.922 times more likely to be in good fitness level than the females. More percentage of females had poor fitness level as compared to male (Female; $75.2 \%$ Vs. Male; $61.2 \%$ ). Same result was almost addressed via the work done by Yoh, T. et al who demonstrated that Asian female international students tend to be especially inactive. For example, Asian female college students averaged only 1.3 hours of physical activity per week, which was substantially less than that amount reported by female college students from North America, Europe, South America, and Africa with average $3.3,2.3,2.2$, and 2.1 hours per week, respectively [26]. Haskell, W. L., et. Al also concluded that Asian women were only obtaining $52 \%$ of the recommended amount of moderate-to-vigorous physical activity necessary to obtain substantial health benefits and they were clearly the least active group overall, which leads to poor physical fitness level [27]. Results on sex differences among college students are inconsistent. Some studies show that male college students participate in more vigorous activities than do their female counterparts. However, others report no differences between male and female college students' physical activity \& thus the fitness [28]. Suminski, R. et al explained that the majority of Asians believe that sport and physical activity participation are predominantly masculine in nature. Such perceptions in Asian countries have resulted in Asian women exhibiting low levels of physical activity during childhood and adolescence [29]. The study among students in Malaysian University also showed that gender has significant connects of physical activity where males are more active in performing physical activity than the females. [30] Because of this mayhem situation, $\mathrm{Zi}$ Yan et al has strongly recommended that there is no doubt that Asian female students are in urgent need of physical activity intervention, particularly given the disastrous effects that physical inactivity has on one's long term health, well-being, and overall functioning [16].

Our study showed that fitness level is significantly associated with differences of DBP during IHGT and baseline recording (autonomic response) with $\mathrm{p}<0.001$. Autonomic response to physical stress in good fitness level students (100\%) was normal ( $\geq 16 \mathrm{mmHg}$ ) however $24.1 \%$ of poor fitness level students had below normal $(\leq 15 \mathrm{mmHg})$ for differences in DBP during IHGT and at rest. So students with good fitness status had adequate response of sympathetic nervous system upon the physical stress (IHGT) 
but students with poor fitness had decrement in the activation of sympathetic nervous system against the physical stress. D Visser DC et al study the adaptation of the cardiovascular system to physical stress for which cardiac output and total peripheral resistance were measured $\&$ found that Heart rate and cardiac output declined significantly more in offspring of hypertensive parents that does not lead to a higher BP response in this group, most probably because of a larger decrease of the cardiac output as compared to offspring of normotensive parents during static exercise [31]. Sala Ret. Al have clarified the role of autonomic nervous system in the management of cardiovascular risk factor \& thus autonomic derangement in poor fitness level students could lead to develop hypertension in future [32]. In contrast to D. Visser DC et al, Bakke EF et al showed similar increase in DBP to two minutes isometric handgrip exercise in two groups as diagnosed Peripheral Atherosclerosis Disease \&control group [33]. Study by Thilip Kumar Gnanaduraiet. et al., on assessment of sympathetic nerve activity by isometric handgrip test in young cigarette smokers, revealed that during isometric exercise the systolic, diastolic blood pressure, heart rate, mean arterial pressure decreased in smokers when compared to non-smokers [34]. Similar type of result was observed in $24 \%$ of poor fitness level students in our study. Such irresponsiveness of sympathetic nervous system to physical exercise in few of the poor fitness level students might indicate that poor fitness level is comparable with imperfect autonomic response but not significantly different. Moderate-to-vigorous physical activity improves the autonomic response, however there is insufficient evidence to conclude a dose and time response effect of physical activity [35], which remain the subject of further research in large population.

\section{Conclusion}

Majority of participants were female and most of the students were with normal BMI, however the fitness level of students was found to be predominantly poor. More proportion of female students had poor fitness. Students with good fitness had normal sympathetic activation to physical stress as compared to poor fitness level students. Minority of poor fitness students had decreased sympathetic response to physical stress. Physical fitness improvement, through physical activity in University students is burgeoning issue, which accentuates the sympathetic activation against pressures encountered through academic journey as well as improves the cognitive functions. With this, there would be significant positive impacts on academic performance \& professional carrier that would benefit the students and the concerned stakeholders.

\section{Disclosure Statement}

All the authors do not have any possible conflicts of interest.

\section{Abbreviations}

\author{
ANS: Autonomic Nervous System \\ BMI: Body Mass Index \\ BP: Blood Pressure \\ CRF: Cardiorespiratory Fitness \\ CSFT: Canadian Standardized Test for Fitness \\ DBP: Diastolic Blood Pressure \\ IHGT: Isometric Hand Grip Test \\ MSNA: Muscle Sympathetic Nerve Activity \\ MVC: Maximum Voluntary Contraction \\ RHR: Recovery Heart Rate \\ SHAS: School of Health and Allied Sciences \\ YMCA: Young Man's Christian Association
}

\section{Funding Details}

This work was supported by School of Health \& Allied Sciences, Pokhara University under Faculty Research Grant [2073-074/2]. There is no role of the funding body in the design of the study and collection, analysis, and interpretation of data and in writing the manuscript.

\section{Ethics Approval and Consent to Participate}

Approval for this study was obtained following proposal review from Institutional Review Committee (IRC) of Pokhara University (Ref. No. 199/074/75). Informed written consent was taken from respondents.

\section{Consent for Publication}

Not applicable.

\section{Availability of Data and Materials}

The datasets generated and/or analyzed during the current study are not publicly available due to privacy policy of the human subject involved in the study but can be made available from the corresponding author on reasonable request.

\section{Acknowledgements}

We would like to acknowledge all the students of "School of Health and Allied Sciences, Pokhara University" participating in this study. Last but not the least, we are indebted to "Faculty of Health Sciences, Pokhara University" for providing the grant as faculty research grant to conduct this research work.

\section{References}

[1] Denolin H. Guidelines for exercise testing and prescription, edited by american college of sports medicine lea \& febiger, philadelphia (1991) 314 pages, illustrated, \$15.00 isbn: 08121-1324-1. Clinical Cardiology. 1992; 15 (2): 139-40. 
[2] Montgomery DL, Reid G, Koziris LP. Reliability and validity of three fitness tests for adults with mental handicaps. Canadian Journal of Sport Sciences. 1992; 17: 309-09.

[3] Pescatello LS, Riebe D, Thompson PD, editors. ACSM's guidelines for exercise testing and prescription. Lippincott Williams \& Wilkins; 2014.

[4] Schumann, A., Andrack, C. and Baer, K. J. Differences of sympathetic and parasympathetic modulation in major depression. Progress in Neuro-Psychopharmacology and Biological Psychiatry. 2017; 79, 324-331.

[5] Hartikainen JE, Tahvanainen KU, Kuusela TA. Short-term measurement of heart rate variability. In Clinical guide to cardiac autonomic tests. Springer, Dordrecht. 1998; pp. 149176.

[6] VAN DEN BERG MP, SMIT AJ. Bedside autonomic function testing in patients with vasovagal syncope. Pacing and clinical electrophysiology. 1997; 20 (8): 2039-42.

[7] Seals DR, Victor RG. Regulation of muscle sympathetic nerve activity during exercise in humans. Exercise and sport sciences reviews. 1991; 19: 313-49.

[8] de Oliveira Sarmento A, da Cruz Santos A, Trombetta IC, Dantas MM, Marques AC, do Nascimento LS, Barbosa BT, Dos Santos MR, do Amparo Andrade M, Jaguaribe-Lima AM, do Socorro Brasileiro-Santos M. Regular physical exercise improves cardiac autonomic and muscle vasodilatory responses to isometric exercise in healthy elderly. Clinical interventions in aging. 2017; 12: 1021.

[9] McCloskey DI, Mitchell JH. Reflex cardiovascular and respiratory responses originating in exercising muscle. The Journal of physiology. 1972; 224 (1): 173-86.

[10] Kiviniemi AM, Perkiömäki N, Auvinen J, Niemelä M, Tammelin T, Puukka K, Ruokonen A, KeinänenKiukaanniemi S, Tulppo MP, Järvelin MR, Jämsä T. Fitness, fatness, physical activity, and autonomic function in midlife. Medicine and Science in Sports and Exercise. 2017; 49 (12): 2459-68.

[11] Belsky DW, Caspi A, Israel S, Blumenthal JA, Poulton R, Moffitt TE. Cardiorespiratory fitness and cognitive function in midlife: neuroprotection or neuroselection? Annals of neurology. 2015; 77 (4): 607-17.

[12] Hallal PC, Andersen LB, Bull FC, Guthold R, Haskell W, Ekelund U, Lancet Physical Activity Series Working Group. Global physical activity levels: surveillance progress, pitfalls, and prospects. The lancet. 2012; 380 (9838): 247-57.

[13] The 3-minute step test by Jason Anderson, Certified Personal Trainer. Available from:

https://www.sparkpeople.com/resource/fitness_articles.asp?id $=1115$.

[14] College Factual ${ }^{\circledR}$. The University of Texas Health Science Center; Diversity Breakdown. Available from: https://www.collegefactual.com/colleges/the-universityoftexashealth-sciencecenter-at-san-antonio/studentlife/diversity/chart-gender diversity.html.

[15] Education matters; Scroll. in. July 14 2016. Available from: https://scroll.in/article/811696/there-are-no-indianuniversities-in-theworlds-top250list-heres-how-javadekar-canchange-that.
[16] Yan Z, Cardinal BJ. Increasing Asian International College Students' Physical Activity Behavior: A Review of the Youth Physical Activity Promotion Model. Health Educator. 2013; 45 (1): $35-45$.

[17] Kenya S, Brodsky M, Divale W, Allegrante JP, Fullilove RE. Effects of immigration on selected health risk behaviors of Black college students. Journal of American college health. 2003; 52 (3): 113-20.

[18] Chen LJ, Fox KR, Ku PW, Taun CY. Fitness change and subsequent academic performance in adolescents. Journal of School Health. 2013; 83 (9): 631-8.

[19] Cardinal BJ, Lee JY, Kim YH, Lee H, Li KK, Si Q. Behavioral, demographic, psychosocial, and sociocultural concomitants of stage of change for physical activity behavior in a mixed-culture sample. American Journal of Health Promotion. 2009; 23 (4): 274-8.

[20] Callaghan P, Eves FF, Norman P, Chang AM, Lung CY. Applying the transtheoretical model of change to exercise in young Chinese people. British journal of health psychology. 2002; 7 (3): 267-82.

[21] Lewis MV, Szabo RA, Weiner KR, McCall L, Piterman L. Cultural barriers to exercise amongst the ethnic elderly. Internet Journal of Health Promotion. 1997: 1-7.

[22] Keating XD, Huang Y, Guan J, Deng M, Zhu L, Dwan C. An examination of southern Chinese collegiate leisure-time exercise patterns. ICHPERSD J Research. 2006; 1 (2): 18-26.

[23] Biddle S, Goudas M. Analysis of children's physical activity and its association with adult encouragement and social cognitive variables. Journal of School Health. 1996; 66 (2): 75-8.

[24] Okely AD, Booth ML, Chey T. Relationships between body composition and fundamental movement skills among children and adolescents. Research quarterly for exercise and sport. 2004; 75 (3): 238-47.

[25] Sallis JF, Owen N. Ecological models. Health behavior and health education: Theory, research, and practice. 1997; 2: 403-24.

[26] Yoh T, Yang H, Gordon B. Status of participation in physical activity among international students attending colleges and universities in the United States. College Student Journal. 2008; 42 (4).

[27] Haskell WL, Lee IM, Pate RR, Powell KE, Blair SN, Franklin BA, Macera CA, Heath GW, Thompson PD, Bauman A. Physical activity and public health: updated recommendation for adults from the American College of Sports Medicine and the American Heart Association. Circulation. 2007; 116 (9): 1081.

[28] Calfas KJ, Sallis JF, Lovato CY, Campbell J. Physical activity and its determinants before and after college graduation. Medicine, Exercise, Nutrition, and Health. 1994; 3 (323-334).

[29] Suminski RR, Petosa R, Utter AC, Zhang JJ. Physical activity among ethnically diverse college students. Journal of American College Health. 2002; 51 (2): 75-80.

[30] Salamudin N, Harun MT. Physical activity index among Malaysian youth. Asian Social Science. 2013; 9 (12): 99.

[31] Barnes VA, Treiber FA, Davis H, Kelley TR, Strong WB. Central adiposity and hemodynamic functioning at rest and during stress in adolescents. International Journal of Obesity (2005). 1998; 22 (11): 1079. 
[32] Sala R, Malacarne M, Pagani M, Lucini D. Association between aerobic fitness and indices of autonomic regulation: cardiovascular risk implications. The Journal of sports medicine and physical fitness. 2015; 56 (6): 794-801.

[33] Bakke EF, Hisdal J, Kroese AJ, Jørgensen JJ, Stranden E. Blood pressure response to isometric exercise in patients with peripheral atherosclerotic disease. Clinical physiology and functional imaging. 2007; 27 (2): 109-15.
[34] Gnanadurai TK, Vajravelu HR, Krishnan P, Balaji R, Ayyavoo S. Assessment of Sympathetic Nerve Activity by Isometric Handgrip Test in Young Cigarette Smokers. Biomedical and Pharmacology Journal. 2016; 9 (2): 623-9.

[35] Oliveira RS, Barker AR, Wilkinson KM, Abbott RA, Williams CA. Is cardiac autonomic function associated with cardiorespiratory fitness and physical activity in children and adolescents? A systematic review of cross-sectional studies. International Journal of Cardiology. 2017; 236: 113-22. 